Thorax (1972), 27, 93.

\title{
Interruption of the aortic arch
}

\author{
ROBIN H. KINSLEY ${ }^{1}$, HESSEL L. UTIAN, DENIS N. FULLER, \\ and PAUL E. MARCHAND
}

Department of Thoracic Surgery, Johannesburg Group of Hospitals and University of the Witwatersrand

Interruption of the aortic arch is an uncommon malformation in which there is no direct continuity between the aortic arch and the descending aorta, the latter arising through a patent ductus arteriosus. Three types are described, depending upon the site of interruption in relation to the arch vessels. A large ventricular septal defect is present in $94 \%$ of cases. It is to be distinguished from aortic arch atresia, which should be regarded as a severe form of preductal coarctation in which the luminal continuity of the arch and descending aorta is absent. Three cases are described: the first demonstrates the natural outcome of the uncorrected anomaly with progression to Eisenmenger's syndrome ; the second illustrates the feasibility of surgical treatment in the neonate; the third is an example of total correction of aortic arch interruption with the common associated anomalies. Diagnosis in infancy is difficult in view of the paucity of definite clinical criteria. Surgery in the infant should consist of reconstruction of the aortic arch together with pulmonary artery banding. In older children total correction can usually be performed electively in a two-stage procedure.

Interruption of the aortic arch is an uncommon anomaly first described in the 18 th century by Raphael Steidele (Roberts, Morrow, and Braunwald, 1962). In a recent review Lie (1967) found reports of 88 cases and added two of his own. An additional 16 cases have since appeared in the English literature (Hairston, Webb, and Lee, 1967 ; Sirak, Resallet, Hosier, and De Lorimer, 1968 ; Rochette, Stanley, Ethier, and Davignon,
1968 ; Tawes et al., 1969 ; Sissman, 1968 ; Reidbord, 1964 ; Tyson, Harris, Nghiem, 1970). The condition differs from atresia of the aortic arch in that complete discontinuity exists between the aortic arch and the descending aorta. Associated cardiac anomalies are almost invariably present.

1Address for reprints: R. H. Kinsley, M.B., B.Ch., F.C.S. (S.A.), 6th Floor, Florence Building, Kotze Street, Hospital Hiil, Johannesburg, South Africa.

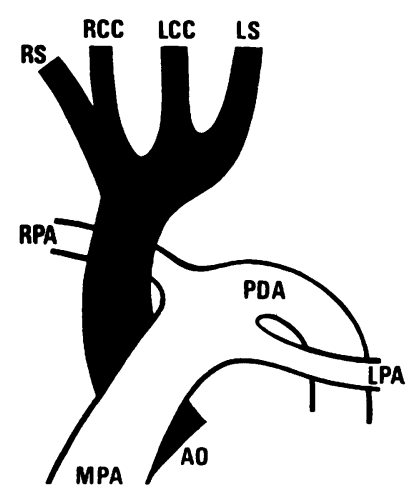

TYPE A

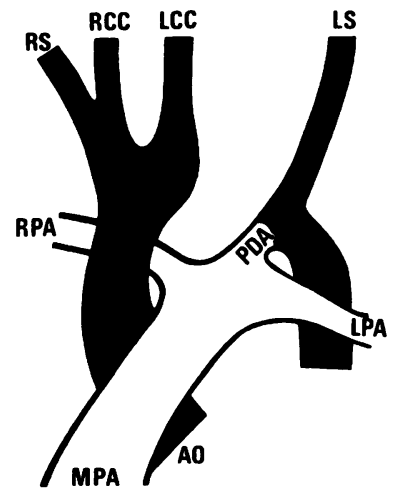

TYPE B

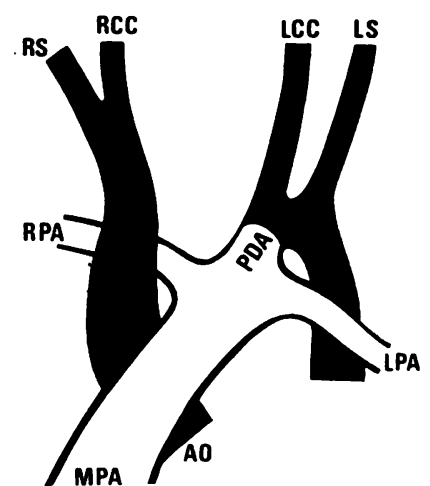

TYPE C

FIG. 1. Three types of interruption of the aortic arch. MPA, main pulmonary artery; Ao, aorta; $R P A$, right pulmonary artery; LPA, left pulmonary artery; $P D A$, patent ductus arteriosus; $R S$, right subclavian artery; $R C C$, right common carotid artery; LCC, left common carotid artery; LS, left subclavian artery. 
Celoria and Patton (1959) recognize three variants (Fig. 1): Type A: the aorta is interrupted distal to the left subclavian artery. Type $B$ : the aorta terminates as the left carotid artery; the left subclavian artery arises from the ductus arteriosus-descending aorta complex. Type $C$ : the aortic arch terminates as the right innominate artery; the left carotid and left innominate arteries both arise from the ductus arteriosusdescending aorta complex.

The development of the various types of interrupted aortic arch is shown in Figure 2. Type A results from total regression or failure of development of the segment of left dorsal aorta between the ductus arteriosus and the left subclavian artery. Type B is presumably a failure of formation of the fourth left aortic arch. The most plausible explanation for the pathogenesis of type $\mathrm{C}$ is that the third and fourth arches fail to develop while the left dorsal aorta between the third and fourth arches (ductus caroticus) persists as the left common carotid artery.

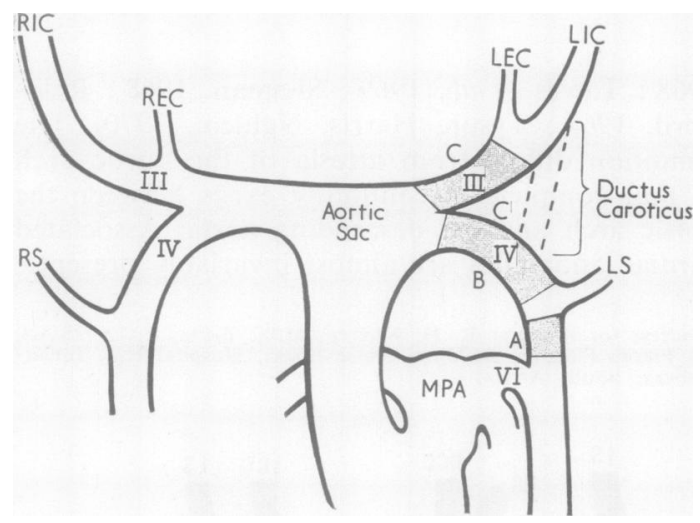

FIG. 2. Development of interruption of the aortic arch. $M P A$, main pulmonary artery; $R S$, right subclavian artery; $L S$, left subclavian artery; RIC, right internal carotid; REC, right external carotid; LEC, left external carotid; LIC, left interna! carotid.

\section{CASE REPORTS}

CASE 1 A 5-month-old girl was admitted on 3 February 1966 with a history of failure to thrive and frequent chest infections. She was not cyanosed nor clubbed. The pulse rate was $144 / \mathrm{min}$ and the systolic blood pressure $130 \mathrm{mmHg}$ in the arms and $120 \mathrm{mmHg}$ in the legs. A grade $3 / 6$ pansystolic murmur was heard at the left sternal border. $\mathbf{A}_{2} \mathrm{P}_{2}$ were closely split. A chest radiograph showed pulmonary plethora and generalized cardiac enlargement. An axis of $140^{\circ}$ with right and possible left ventricular hypertrophy was noted on the electrocardiogram (Fig. 3).
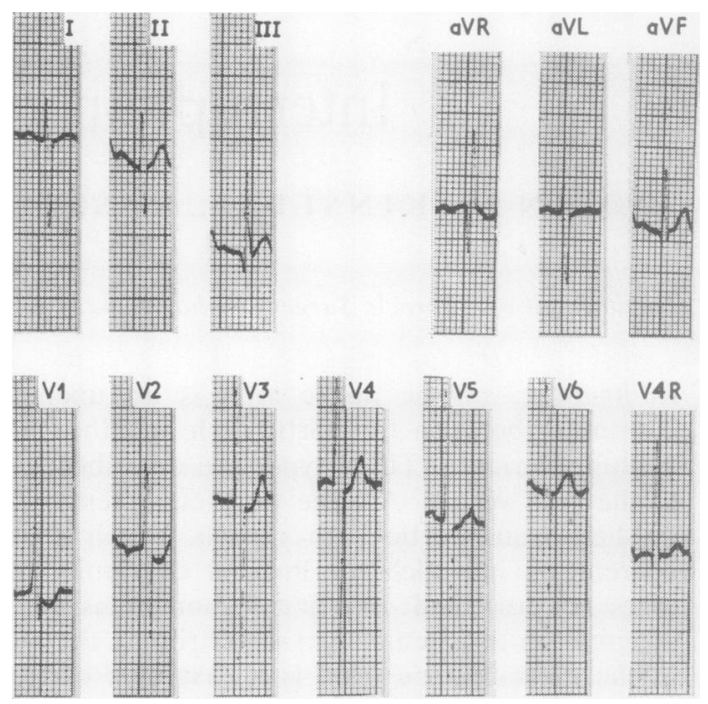

FIG. 3. Case 1. Electrocardiogram.

A large ventricular septal defect was diagnosed and the child was treated medically. At 1 year, cardiac catheterization was undertaken because of persistent cardiac failure, and a large left-to-right ventricular shunt with balanced pressures was confirmed. It was necessary to abandon prematurely the procedure because of arrhythmia, but not before the catheter had passed into the descending aorta through a relatively posteriorly situated vessel presumed, at the time, to be the ascending aorta.

On 21 September 1966, a left thoracotomy was performed with the object of banding the pulmonary artery. A type A aortic arch interruption was found with a massively dilated and tense main pulmonary artery. The surgeon did nothing because he believed the lesion could not be corrected. Since then gradual progression of the pulmonary vascular resistance to an Eisenmenger lung has occurred (Fig. 4). The child, now $4 \frac{1}{2}$ years old, has generalized cyanosis, clubbing, right ventricular hypertrophy, and marked right axis deviation.

CASE 2 A 6-day-old female weighing $6 \mathrm{lb} 6 \mathrm{oz}(2 \cdot 9$ kg) was admitted to hospital on 27 September 1969 because of feeding difficulties and breathlessness. She was not clinically cyanosed; the respiratory rate was $90 / \mathrm{min}$ and the pulse rate $160 / \mathrm{min}$. Femoral pulses were not palpable. By the flush technique the systolic pressure in the legs was $40 \mathrm{mmHg}$ and in the arms $75 \mathrm{mmHg}$. A summation gallop and a systolic murmur were heard over the whole precordium. Radiological cardiomegaly with pulmonary plethora was present (Fig. 5a) with electrocardiographic evidence of right ventricular hypertrophy and marked right axis deviation (Fig. 6). A diagnosis of coarctation of the aorta with a ventricular septal defect was made 


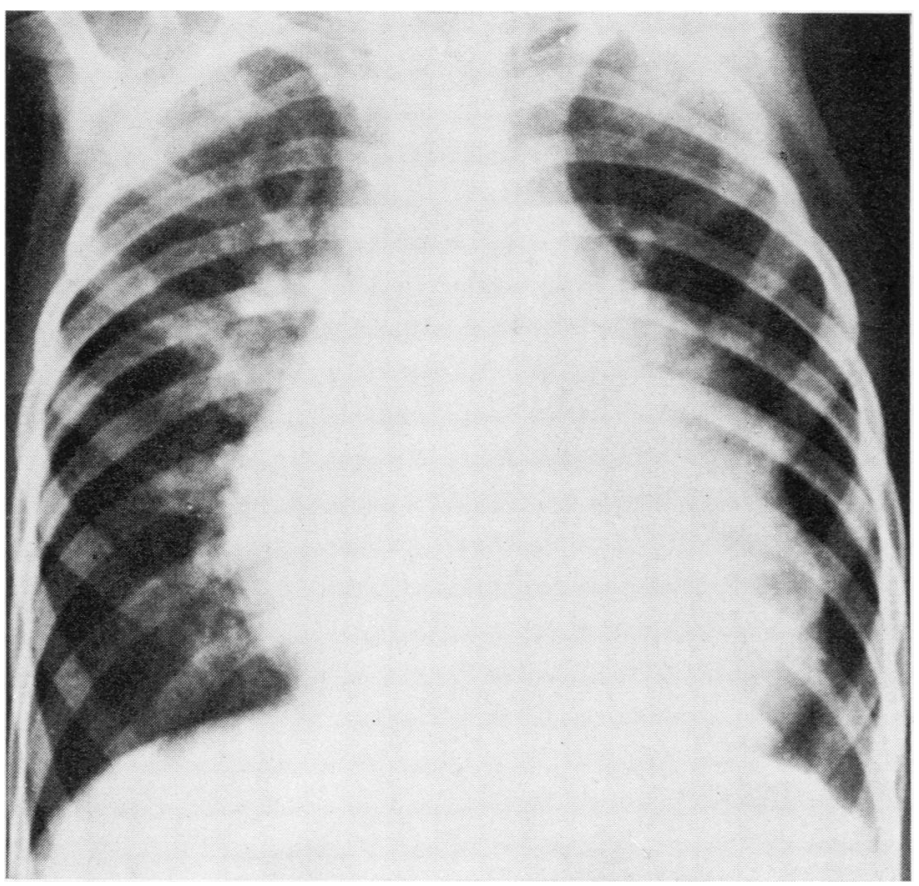

FIG. 4. Case 1. Chest radiograph aged $4 \frac{1}{2}$ years.

clinically. The child was given digitalis but did not improve and on the eighth day of life it was decided to operate. A type A interruption of the aortic arch was found. The origin of the ductus from the pulmonary artery was moderately coarcted. The coarcted ductus was excised and the distal aorta was anastomosed to the terminal aortic arch at the base of the left subclavian artery. A massive tense pulmonary trunk was banded to narrow the lumen approximately $50 \%$ and to produce a strong thrill in the distal pulmonary artery.

Postoperatively she required 10 days of endotracheal intubation and intermittent positive pressure respiration. She was discharged from hospital five weeks after admission with easily palpable femoral pulses. She remains well, aged 1 year. A recent radiograph (Fig. 5b) shows reduction in the relative cardiac size and a decrease in pulmonary vascularity.

CASE 3 A male infant was seen on 2 February 1966 at the age of 4 months because of frequent respiratory infections and failure to thrive. Mild cardiac failure was present and a loud pansystolic murmur was heard over the whole precordium. The systolic pressures were $90 \mathrm{mmHg}$ in the arms and $50 \mathrm{mmHg}$ in the legs. A radiograph of the chest (Fig. 7a) showed cardiomegaly and pulmonary plethora. An electrocardiogram (Fig. 8) revealed an axis of $+150^{\circ}$ together with left and right ventricular hypertrophy. A diagnosis of coarctation of the aorta with ventri- cular septal defect was made clinically. The child was given digitalis and diuretics with good response. At the age of 3 years he was re-admitted with bronchitis. Moderately severe pulmonary hypertension with close splitting of $\mathbf{A}_{2} \mathbf{P}_{2}$ and a pulmonary incompetent murmur were present. The chest film (Fig. 7b) again showed pulmonary plethora, possibly with peripheral pulmonary arterial attenuation and considerable cardiomegaly. In view of the increasing pulmonary hypertension it was decided to correct the coarctation in the hope of lessening left ventricular systolic pressure and consequently the left-to-right shunt. At operation on 16 October 1968 a type B interruption of the aortic arch was found. A Dacron tube graft was introduced between the aortic arch and the descending aorta, with division of the ductus. Postoperatively the signs of pulmonary hypertension remained unchanged and six months later cardiac catheterization revealed a main pulmonary artery pressure of $65 / 25 \mathrm{mmHg}$ (mean $45 \mathrm{mmHg}$ ) and right ventricular pressure $65 / 0 \mathrm{mmHg}$. The left-to-right shunt was estimated to be $355 \mathrm{ml} / \mathrm{min}$ and pulmonary vascular resistance $5 \cdot 1$ Wood units. Angiography confirmed the ventricular septal defect and revealed wide patency of the aortic graft. On 19 March 1969, under cardiopulmonary bypass, a $1-\mathrm{cm}$ ventricular septal defect was closed with a Teflon patch. Intraoperative recordings showed that the pulmonary artery pressure was reduced from $55 \mathrm{mmHg}$ to $44 \mathrm{mmHg}$. 
(a)
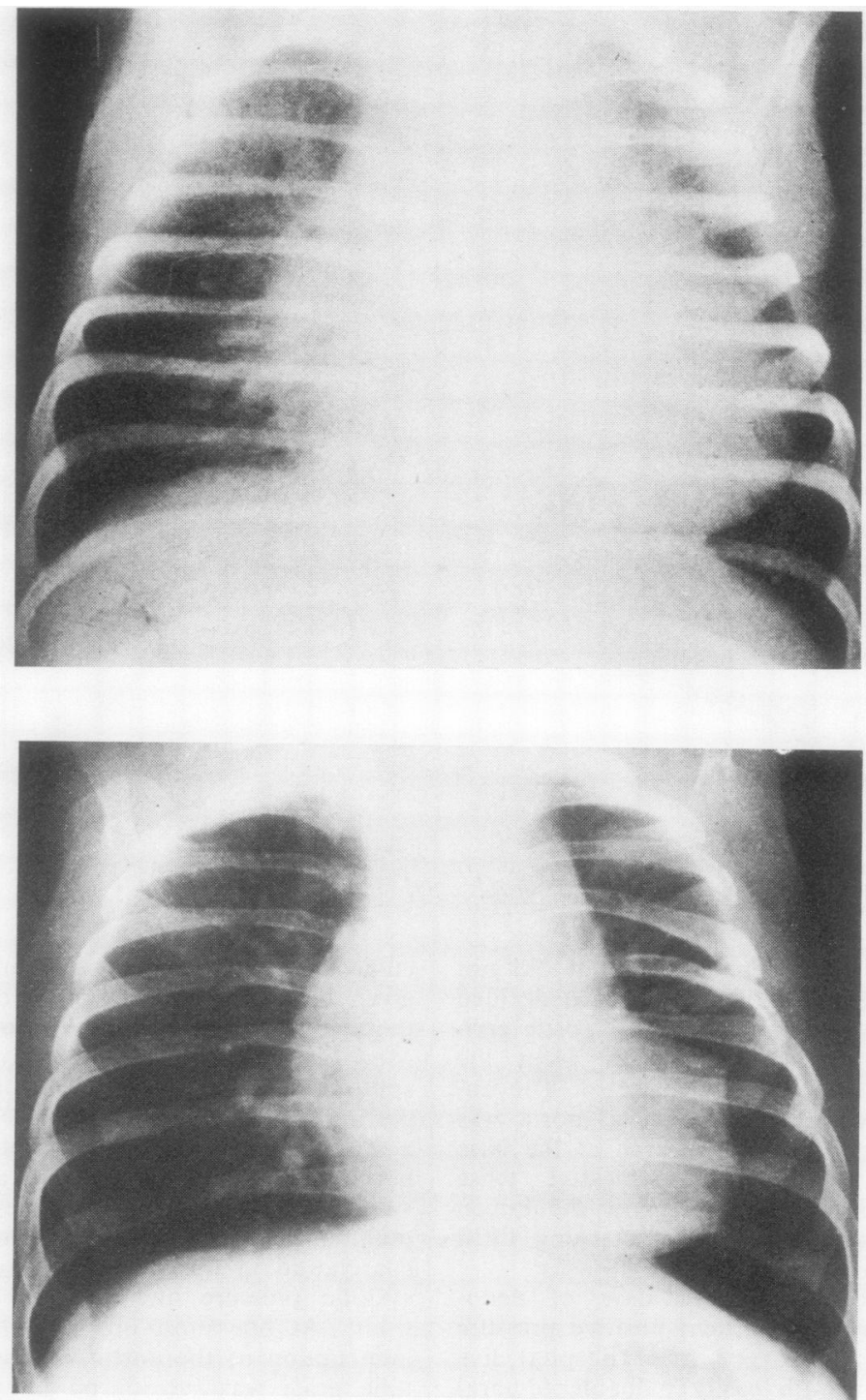

FIG. 5. Case 2. (a) Preoperative chest radiograph; (b) 1 year postoperative.

Sixteen months later the child is well and active. An aortic systolic murmur is present, possibly due to the bicuspid aortic valve. The blood pressure in the upper and lower extremities is equal and the pulmonary plethora has decreased (Fig. 7c).

\section{DISCUSSION}

More than $80 \%$ of cases of interrupted aortic arch are diagnosed only after death, largely because the condition is masked by associated cardiac anomalies. A large ventricular septal defect, said to be in a relatively anterior location (Roberts et al., 1962), is present in 94\% (Tawes et al., 1969) of cases. The pulmonary artery overrides the ventricular septum to a variable degree (Edwards, Carey, Neufeld, and Lester, 1965) and this may cause the pulmonary artery to be mistaken for the aorta, as occurred in case 1. EvertsSuárez and Carson (1959) suggested that the 

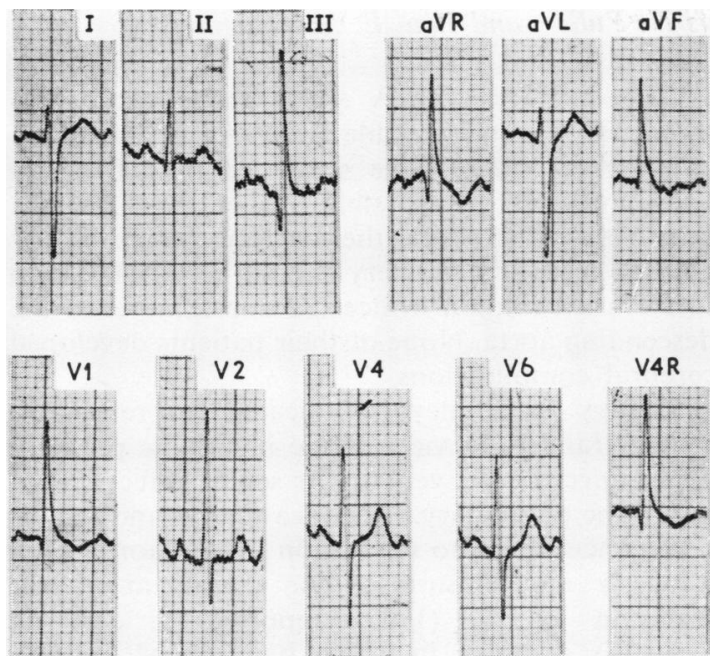

FIG. 6. Case 2. Electrocardiogram.

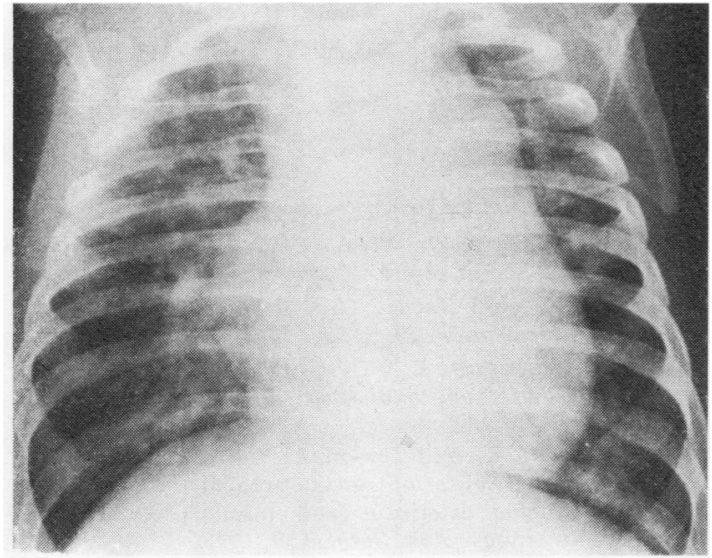

(a)

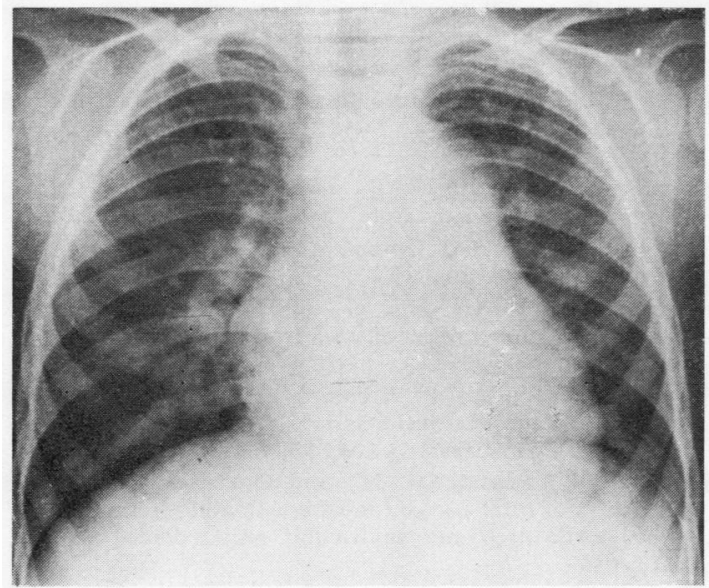

(b)

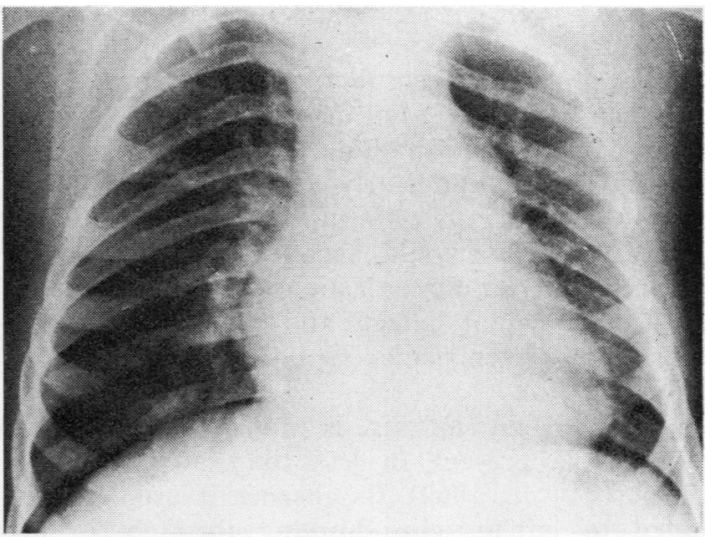

(c)

FIG. 7. Case 3. Chest radiographs (a) aged 4 months; (b) aged 3 years; (c) postoperative, aged $4 \frac{1}{2}$ years.
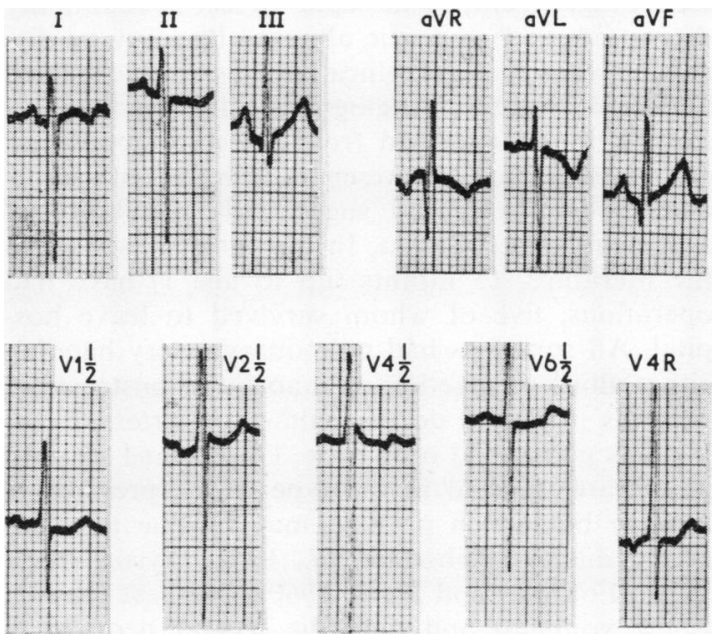

FIG. 8. Case 3. Electrocardiogram.

common association of a ventricular septal defect with a patent ductus arteriosus and aortic interruption constituted a specific cardiovascular trilogy. Other associated anomalies include hypoplasia of the proximal aorta, bicuspid aortic valve, subaortic stenosis, mitral stenosis or atresia, persistent truncus arteriosus, double outlet right ventricle, and anomalous origin of the right subclavian artery. Lie (1967) uses the all embracing term Steidele's complex to describe any congenital malformation complex which includes disconnexion of the ascending and descending aorta. The 
cardiac abnormality probably derives from a disturbance of conal septal development with deviation of the infundibular septum leftwards, posteriorly, and inferiorly, resulting in malalignment of the conus with the ventricular septum. This hypothesis would account for its frequent association with hypoplastic left heart lesions, a ventricular septal defect, and the variable overriding of the ventricular septal defect by the pulmonary trunk.

Diagnosis in infants is difficult. Differential cyanosis is present in less than $30 \%$ of cases (Roberts et al., 1962). Its absence is usually attributed to left-to-right shunting through an unrestrictive ventricular septal defect, although a large collateral circulation (Pillsbury, Lower, Shumway, 1964 ; Daves and Treger, 1964) and the co-existence of acrocyanosis, frequent in neonates, are other factors. Absence or diminution of femoral pulses is rare because balanced ventricular pressures are usual (Roberts et al., 1962). Not surprisingly, ventricular septal defect is commonly diagnosed, and an aortic abnormality may be discovered only angiographically or as an unexpected finding at surgery. Angiographically, interruption cannot be distinguished from atresia or preductal coarctation, but the presence of balanced ventricular pressures should suggest the possibility of aortic arch interruption. In the cases presented in the literature, 15 infants (up to age 1) have had operations, five of whom survived to leave hospital. All survivors had pulmonary artery banding either alone or together with aortic reconstruction, whereas in the 10 deaths pulmonary artery banding was performed only once. Diminished femoral pulses are unusual in the type which presents in infancy but, when present, may be due to a coarcted ductus (Roberts et al., 1962 ; Tyson et al., 1970 ; Fournier and Zaidi, 1960). Our case (case 2) is the youngest and only the second neonate to have survived reconstruction of an interrupted aortic arch. It is proposed eventually to attempt total correction.

Older children are a naturally selected group because of a restricted or absent ventricular septal defect, a good systemic collateral circulation, and (or) an elevated pulmonary vascular resistance (case 1). Diminution of femoral pulses is usual and recognition of an aortic abnormality should not be missed. The literature describes six cases treated by aortic reconstruction without pulmonary artery banding, and five survived. Our case 3 is the patent ductus arteriosus, aortic arch interruption and ventricular septal defect triad, reported by Singh, Bentall, and Oakley (1970).
Correction of type A aortic arch interruption should always be possible by direct anastomosis. Sirak et al. (1968) have suggested that, if direct anastomosis is not possible, rather than insert a prosthetic graft, both the left subclavian artery and the left carotid artery should be turned down to form a common orifice for anastomosis to the descending aorta. None of their patients developed cerebral complications.

Surgery in infancy is indicated for refractory cardiac failure. In view of the invariable presence of an unrestrictive ventricular septal defect, banding of the pulmonary artery is a logical and important concomitant to correction of the aortic arch anomaly and closure of the ductus arteriosus. Hairston et al. (1967) reported a case of Steidele's complex in which banding of the pulmonary artery alone produced a dramatic improvement and survival of the patient. Banding may also prevent the development of irreversible elevation of pulmonary vascular resistance, a possible outcome in patients surviving infancy without surgery (case 1).

\section{REFERENCES}

Celoria, G. C., and Patton, R. B. (1959). Congenital absence of the aortic arch. Amer. Heart J., 58, 407.

Daves, M. L., and Treger, A. (1964). Vertebral grand larceny. Circulation, 29, 911.

Edwards, J. E., Carey, L. S., Neufeld, H. N., and Lester, R. G. (1965). Congenital Heart Disease, vol. 1, p. 162. Saunders, Philadelphia.

Everts-Suárez, E. A., and Carson, C. P. (1959). The triad of congenital absence of aortic arch (isthmus aortae), patent ductus arteriosus and interventricular septal defect-a trilogy. Ann. Surg., 150, 153.

Fournier, P., and Zaidi, Z. H. (1960). Congenital absence of the aortic arch. Amer. Heart J., 59, 148.

Hairston, P., Webb, H., and Lee, W. H. (1967). Aortic arch interruption: treatment with pulmonary artery banding. J. thorac. cardiovasc. Surg., 54, 60.

Lie, J. T. (1967). The malformation complex of the absence of the arch of the aorta-Steidele's complex. Amer. Heart $J ., 73,615$.

Pillsbury, R. C., Lower, R. R., and Shumway, N. E. (1964). Atresia of the aortic arch. Circulation, 30, 749.

Reidbord, H. E. (1964). Complete interruption of the aortic $\mathrm{\omega}$ arch. J. Lancet, 84, 339.

Roberts, W. C., Morrow, A. G., and Braunwald, E. (1962). Complete interruption of the aortic arch. Circulation, 26, 39.

Rochette, M., Stanley, P., Ethier, M. F., and Davignon, A. (1968). Complete interruption of the aortic arch in infancy. Canad. med. Ass. J., 98, 131.

Singh, M. P., Bentall, H. H., and Oakley, C. M. (1970). Successful total correction of congenital interruption of $\frac{\Omega}{\mathbb{D}}$ the aortic arch and ventricular septal defect. Thorax, 25, 615 . 
Sirak, H. D., Resallet, M., Hosier, D. M., and De Lorimer, A. A. (1968). A new operation for repairing aortic arch atresia in infancy. A report of three cases. Circulation, 37, 43 (Suppl. II).

Sissman, M. J. (1968). Anomalies of the aortic arch complex, In: Heart Disease in Infants, Children and Adolescents, edited by A. J. Moss and F. H. Adams, chap. 19. Williams and Wilkins, Baltimore.
Tawes, R. L., Panagopoulos, P., Aberdeen, E., Waterston, D. J., and Bonham-Carter, R. E. (1969). Aortic arch atresia and interruption of the aortic arch. Experience in 11 cases of operation. J. thorac. cardiovasc. Surg., 58, 492.

Tyson, K. R. T., Harris, L. C., and Nghiem, Q. X. (1970). Repair of aortic arch interruption in the neonate. Surgery, 67, 1006. 